\title{
Mutations and Overexpression of CYP51 Associated with DMI-Resistance in Colletotrichum gloeosporioides from Chili
}

\author{
Ling-ling Wei, ${ }^{1}$ Wen-chan Chen, ${ }^{1}$ Wei-cheng Zhao, ${ }^{1}$ Jin Wang, ${ }^{1}$ Bing-ran Wang, ${ }^{1}$ Feng-jie Li, ${ }^{1}$ Meng-di Wei, ${ }^{1}$ Jun Guo, ${ }^{2}$ \\ Chang-jun Chen, ${ }^{1, \dagger}$ Jia-qiu Zheng, ${ }^{2, \dagger}$ and Kai Wang ${ }^{2, \dagger}$ \\ ${ }^{1}$ College of Plant Protection, Nanjing Agricultural University, Key Laboratory of Pesticide, Jiangsu Province, Nanjing 210095, \\ China \\ ${ }^{2}$ Agricultural Science Institute of Yancheng, Jiangsu Province, Yancheng 224000, China
}

\begin{abstract}
Chili anthracnose caused by Colletotrichum spp. is an annual production concern for growers in China. Sterol C14-demethylation inhibitors (DMIs, such as tebuconazole) have been widely used to control this disease for more than three decades. In the current study, of 48 isolates collected from commercial chili farms in Jiangsu Province of China during 2018 and 2019, 8 single-spore isolates were identified as Colletotrichum gloeosporioides and the rest were identified as C. acutatum. To determine whether the DMI resistance of isolates develops in the field, mycelial growth of the 48 isolates was measured in culture medium with and without tebuconazole. In all, 6 of the 8 C. gloeosporioides isolates were resistant to tebuconazole, but all 40 of the $C$. acutatum isolates were sensitive to tebuconazole. The fitness cost of resistance was low based on a comparison of fitness parameters between the sensitive and resistant isolates of $C$. gloeosporioides. Positive cross-resistance

mutations can be divided into three genotypes. Genotype I possessed four substitutions (V18F, L58V, S175P, and P341A) at the CgCYP51A gene but no substitutions at $C g C Y P 51 B$, while genotype II had five substitutions (L58V, S175P, A340S, T379A, and N476T) at $C g C Y P 51 A$, concomitant with three substitutions (D121N, T132A, and F391Y) at $C g C Y P 51 B$. In addition, genotype III contained two substitutions (L58V and S175P) at $C g C Y P 51 A$, concomitant with one substitution (T262A) at $C g C Y P 51 B$. Molecular docking models illustrated that the affinity of tebuconazole to the binding site of the CgCYP51 protein from the resistant isolates was decreased when compared with binding site affinity of the sensitive isolates. Our findings provide not only novel insights into understanding the resistance mechanism to DMIs, but also some important references for resistance management of C. gloeosporioides on chili.
\end{abstract} was observed between tebuconazole and difenconazole or propiconazole, but not prochloraz. Alignment results of the CgCYP51 amino acid sequences from the sensitive and resistant isolates indicated that
Keywords: chili, Colletotrichum gloeosporioides, DMI resistance, fitness, resistant mechanism
Chili is among the most popular vegetables worldwide, because it has high nutritional and economic value in both developed and developing countries (Than et al. 2008). Chili favors tropical and subtropical climates where anthracnose often occurs such as Korea, China (Cao et al. 2017; Li et al. 2005; Shin et al. 2000), and America (Harp et al. 2013). Anthracnose ranks the ninth among the most severe diseases worldwide, causing considerable yield loss worldwide (Lewis Ivey et al. 2004; Ramdial and Rampersad 2015). Furthermore, more than 167 species of Colletotrichum are documented to cause the disease on hundreds of plants (Zhang et al. 2017), including watermelon (Monroe and Santini 1997), grapevine (Jang et al. 2011), strawberry (Lin et al. 2016), pepper (Zhang et al. 2017), apple, pear (Ivic et al. 2013), and other economic crops (Phoulivong et al. 2010). In addition, at least four species of Colletotrichum have been isolated from pepper (Lamsal et al. 2012; Lewis Ivey et al. 2004; Zhang et al. 2017), including Colletotrichum gloeosporioides, C. acutatum, C. truncatum, and C. coccodes.

Because highly anthracnose-resistant varieties are unavailable, agrochemicals are relied upon to control anthracnose. Benzimidazole

${ }^{\dagger}$ Corresponding authors: C.-j. Chen; changjun-chen@njau.edu.cn; K. Wang; 13851051048@163.com; and J.-q. Zheng;nky8236@163.com

Funding: This work was supported by the Chinese Key R \& D Plan (2016YED0201007, 2018YFD0201201, and 2018YFD0201000), Agricultural Science and Technology Projects of Jiangsu Province, China (PZCZ201715 and CX(18)2005), and Postgraduate Research \& Practice Innovation Program of Jiangsu Province (No. KYCX18_0670).

The author(s) declare no conflict of interest.

Accepted for publication 25 October 2019.

(C) 2020 The American Phytopathological Society derivatives (abbreviated as MBCs; e.g., carbendazim) and sterol C14demethylation inhibitors (DMIs; e.g., tebuconazole, difenoconazole, and propiconazole) are extensively used to control this disease (Gisi and Sierotzki 2008; Sierotzki and Scalliet 2013; Xu et al. 2014). MBCs act on the assemblage of tubules from the heterodimer of $\alpha$ - and $\beta$ tubulins (Davidse 1986). However, DMIs interfere with fungal growth by inhibiting the cytochrome $\mathrm{P} 450$ sterol $14 \alpha$-demethylase (CYP51) in the biosynthesis of sterol for fungal membranes (Ziogas and Malandrakis 2015). Unfortunately, MBC-resistant populations of Colletotrichum spp. have been reported from grape, strawberry, annual bluegrass or bent grass, banana, and bean since 1973 (Chen et al. 2013; Ishii et al. 2016; Leadbeater and Thind 2012; Yang et al. 2015). Three mechanisms of resistance to DMIs alone or in combination have been documented: (i) modification at CYP51 (Cañas-Gutiérrez et al. 2009; Chen et al. 2005; Chowdhary et al. 2012; Délye et al. 1997, 1998; Mann et al. 2003), (ii) overexpression of CYP51 (Hamamoto et al. 2000; Rodriguez-Tudela et al. 2008), and (iii) increased drug efflux pumps, including ATP-binding cassette transporters and major facilitator systems (Perea et al. 2001; Sanglard et al. 1995; Schnabel and Jones 2001).

In China, chili anthracnose is caused mainly by $C$. acutatum and $C$. gloeosporioides (Gao et al. 2017; Liao et al. 2012). Recently, farmers have complained about the decreased efficacy of the DMIs in controlling anthracnose in commercial chili fields at Yancheng of Jiangsu Province in China. To investigate whether DMI resistance develops in the fungus, the objectives of this study were to (i) assess the sensitivity of isolates collected to tebuconazole, (ii) reveal the possible molecular resistant mechanism, (iii) determine crossresistance patterns between tebuconazole and the other DMIs or other fungicides with different mode of action, and (iv) characterize the fitness of tebuconazole-resistant isolates.

\section{Materials and Methods}

Isolation and identification of $\boldsymbol{C}$. gloeosporioides. During summer 2018 to 2019, mature fruit of chili (Capsicum annuum) with 
lesions typical of anthracnose were sampled from Yancheng (YC) in Jiangsu Province of China. Small pieces of tissue cut from the margin of lesions on the surface of fruit were disinfected in $1 \% \mathrm{NaClO}$ for $3 \mathrm{~min}$, dipped in $75 \%$ ethanol for $3 \mathrm{~s}$, washed three times with sterile water, placed on potato dextrose agar (PDA) plates supplemented with streptomycin sulfate, and incubated at $25^{\circ} \mathrm{C}$ in darkness. On the fourth day, a mycelia plug of each isolate was transferred to new PDA plates. After incubation at $25^{\circ} \mathrm{C}$ in darkness for 7 days, a single spore of each isolate was microscopically selected, then moved to a fresh PDA plate supplemented with streptomycin sulfate. In total, 48 single-spore isolates were obtained and stored on PDA slants at $4{ }^{\circ} \mathrm{C}$. DNA was extracted from mycelia of each isolate by the cetyltrimethylammonium bromide method (Ristaino et al. 1998). All isolates were further identified by amplification with primer pairs ITS1/ITS4 and TUBF/TUBR (Table 1) (Weir et al. 2012). The internal transcribed spacer (ITS) and $\beta$-tubulin sequences of each isolate were blasted in the NCBI GenBank database to further identify the isolates.

Fungicides and culture medium. Technical-grade fungicides, including tebuconazole (95\% active ingredient [a.i.]), difenoconazole (96.5\% a.i.), propiconazole ( $98 \%$ a.i.), prochloraz ( $96.5 \%$ a.i.), fluazinam (97\% a.i.), fludioxonil (97.5\% a.i.), and azoxystrobin (96\% a.i.), were provided by Best-Reagent (Chengdu, China), and salicylhydroxamic acid (SHAM) (99\% a.i.) was purchased from Aldrich Co. (Milwaukee, WI, U.S.A.). Tebuconazole, difenoconazole, propiconazole, prochloraz, fluazinam, fludioxonil, and SHAM were prepared in methanol, and azoxystrobin was dissolved in acetone, as stock solutions of $10^{4} \mu \mathrm{g} / \mathrm{ml}$ concentration.

PDA was composed of a broth of $200 \mathrm{~g}$ of potato, $20 \mathrm{~g}$ of dextrose, and $16 \mathrm{~g}$ of agar powder in 1 liter of distilled water. Alkyl ester agar (AEA) was prepared with $6 \mathrm{~g}$ of sodium nitrate, $20 \mathrm{ml}$ of glycerol, $5 \mathrm{~g}$ of yeast extract, $16 \mathrm{~g}$ of agar powder, $1.5 \mathrm{~g}$ of potassium dihydrogen phosphate, $0.5 \mathrm{~g}$ of potassium chloride, and $0.51 \mathrm{~g}$ of magnesium sulfate heptahydrate in 1 liter of distilled water. Water agar (WA) consisted of $15 \mathrm{~g}$ of agar powder per liter of distilled water. Potato dextrose broth (PDB) was prepared with the broth of $200 \mathrm{~g}$ of potato and $20 \mathrm{~g}$ of dextrose in 1 liter of distilled water.

Sensitivity of isolates to tebuconazole. To evaluate tebuconazole sensitivity, a mycelia plug ( $5 \mathrm{~mm}$ in diameter) of each isolate was transferred on the center of PDA plates supplemented with tebuconazole at $10 \mu \mathrm{g} / \mathrm{ml}$ (Xu et al. 2014; Zhang et al. 2012). Petri dishes were incubated at $25^{\circ} \mathrm{C}$ in darkness for 5 days. If the isolate grew, it was considered resistant to tebuconazole. If the isolate did not grow, it was considered sensitive. Each isolate was tested in triplicate and the entire experiment was repeated three times.

Mycelia growth, sporulation, and germination rates of C. gloeosporioides. A fresh mycelia plug of each isolate was transferred on PDA plates and incubated at $25^{\circ} \mathrm{C}$ in darkness for 5 days; then, colony diameters were measured twice, perpendicularly, and averaged. For determination of spore production, mycelia plugs were

Table 2. Fungicide concentrations used to determine cross-resistance

\begin{tabular}{ll}
\hline Fungicide & \multicolumn{1}{c}{ Concentration $(\boldsymbol{\mu g} / \mathbf{m l})$} \\
\hline Difenoconazole, propiconazole & $0,0.125,0.25,0.5,1,2$ \\
Prochloraz & $0,0.0037,0.011,0.033,0.1,0.3$ \\
Azoxystrobin & $0,0.012,0.037,0.11,0.33,1$ \\
Fluazinam & $0,0.0098,0.030,0.089,0.27,0.8$ \\
Fludioxonil & $0,0.012,0.037,0.11,0.33,1$ \\
\hline
\end{tabular}

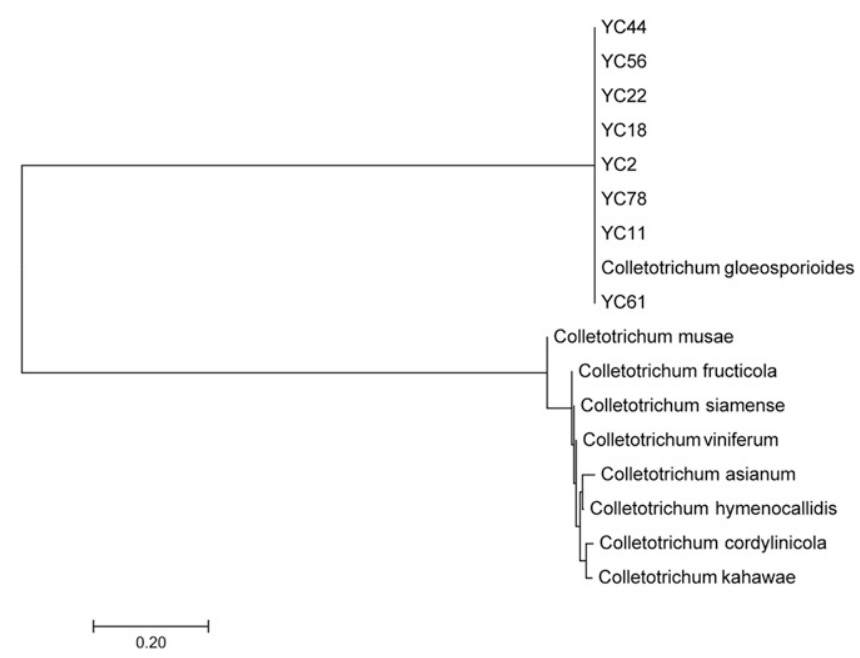

Fig. 1. Phylogram generated from maximum parsimony analysis based on sequences of internal transcribed spacers and $\beta$-tubulin, showing the phylogenetic relationship between Colletotrichum gloeosporioides and the isolates tested in the study.

Table 1. Primers utilized in this study

\begin{tabular}{|c|c|c|c|}
\hline Primers & Sequence $\left(5^{\prime} \rightarrow 3^{\prime}\right)$ & Reference & Description \\
\hline ITS1 & TCCGTAGGTGAACCTGCGG & Weir et al. 2012 & Amplification of ITS to identify Colletotrichum gloeosporioides \\
\hline ITS4 & TCCTCCGCTTATTGATATGC & $\ldots$ & $\ldots$ \\
\hline TUBF & AACATGCGTGAGATTGTAAGT & Weir et al. 2012 & Amplification of $\beta$-tubulin to identify $C$. gloeosporioides \\
\hline TUBR & TAGTGACCCTTGGCCCAGTTG & $\ldots$ & $\ldots$ \\
\hline AF1 & ATCAGCAACAGTTCGTCCCG & $\ldots$ & Amplification of the 5'-UTR region of the $C g C Y P 51 A$ gene \\
\hline AR1 & GAAGACGGTTGGTGGTAAT & $\ldots$ & $\ldots$ \\
\hline BF1 & AATCATTCCCGTCTCCC & $\ldots$ & Amplification of the 5'-UTR region of the $C g C Y P 51 B$ gene \\
\hline BR1 & GGCTCGTTGGCGTTCTT & $\ldots$ & $\ldots$ \\
\hline AF2 & ATGATGGAAGGCATAGAACTTC & $\ldots$ & Amplification of the $C g C Y P 51 A$ gene \\
\hline AR2 & TTCTTGACTTTGCGGAGGA & $\ldots$ & $\ldots$ \\
\hline AF3 & TTCCTCTTCCCTTGGTTGC & $\ldots$ & $\ldots$ \\
\hline AR3 & TCAATCACGTCGGGTCCACC & $\ldots$ & $\ldots$ \\
\hline $\mathrm{BF} 2$ & ATGGGTCTCCTGCAGGAGG & $\ldots$ & Amplification of the $C g C Y P 51 B$ gene \\
\hline BR2 & TGGGCGAGACGGAGCATA & $\ldots$ & $\ldots$ \\
\hline BF3 & TTTTCACCGCTTCCCACG & $\ldots$ & $\ldots$ \\
\hline BR3 & TTACGCCTCACGCTTCTCCCAG & $\ldots$ & $\ldots$ \\
\hline RT-AF & TCACATTCACCCTCTTCGGC & $\ldots$ & Quantitative RT-PCR primers for analysis of $C g C Y P 51 A$ expression \\
\hline RT-AR & CGGGGGCAGTCTTGATGTAG & $\ldots$ & $\ldots$ \\
\hline RT-BF & CATTTTCACCGCTTCCCACG & $\ldots$ & Quantitative RT-PCR primers for analysis of $C g C Y P 51 B$ expression \\
\hline RT-BR & GTGCCGTTCTTGTAGGTGGA & $\ldots$ & $\ldots$ \\
\hline RT-TubGF & TCTCGATGTTATCCGCCG & $\ldots$ & Amplification of the $\beta$-tubulin gene \\
\hline RT-TubGR & TGAGCTCAGGAACACTGACG & $\ldots$ & $\ldots$ \\
\hline
\end{tabular}

${ }^{\mathrm{z}}$ ITS $=$ internal transcribed spacer, UTR = untranslated region, and RT = reverse-transcription. 
inoculated on AEA plates at $25^{\circ} \mathrm{C}$ in darkness for 7 days; then, spores were harvested by rinsing the colonies with $10 \mathrm{ml}$ of distilled water and spore concentration in the filtered spore suspension was determined by a hemocytometer. To determine the rate of spore germination, a $20-\mu l$ spore suspension (approximately $10^{5}$ to $10^{6}$ spores $/ \mathrm{ml}$ ) was uniformly distributed onto a WA plate and, after incubation at $25^{\circ} \mathrm{C}$ in darkness for $4 \mathrm{~h}, 100$ spores of each plate were investigated by microscopic observation. The spore was considered to be germinated when the length of the spore bud tube was equal to or longer than its short diameter. Each isolate was repeated with three plates, and the experiment was performed three times.

Pathogenicity test. Pathogenicity of the eight $C$. gloeosporioides isolates was determined by inoculation of mature fruits of chili and strawberry. Briefly, a mycelia plug of each isolate was placed on an artificial wound on the fruit surface. The lesions were measured after 5 days at $25^{\circ} \mathrm{C}$ with $12 \mathrm{~h}$ of light per day. Each treatment had three replicate fruits and the experiment was conducted three times.

Cross-resistance assay. The sensitivities of the eight $C$. gloeosporioides isolates to three DMIs (i.e., difenoconazole, propiconazole, and prochloraz), one phenylpyrrole fungicide (fludioxonil), and one oxidative phosphorylation uncoupler (fluazinam) were determined using different fungicide doses (Table 2) and estimating effective concentrations for $50 \%$ mycelia growth inhibition $\left(\mathrm{EC}_{50}\right)$ values of mycelia growth inhibition. Meanwhile, the sensitivity to one quinone outside inhibitor (azoxystrobin) was similarly determined for spore-germination inhibition. Each treatment had three replicate plates, and the experiment was performed three times.
Sequencing of the whole nucleotide sequences of CgCYP51. The genomic DNA of each isolate was extracted as previously described. Primer pairs $\mathrm{AF}_{2} / \mathrm{AR}_{2}, \mathrm{AF}_{3} / \mathrm{AR}_{3}, \mathrm{BF}_{2} / \mathrm{BR}_{2}$, and $\mathrm{BF}_{3} / \mathrm{BR}_{3}$ (Table 1) were designed to amplify the open reading frames of $C g C Y P 51 A$ and $C g C Y P 51 B$ from resistant and sensitive isolates. To examine whether overexpression of $C g C Y P 51$ genes could be caused by mutation at the $5^{\prime}$ untranslated region ( $5^{\prime}$-UTR), primer pairs $\mathrm{AF}_{1} / \mathrm{AR}_{1}$ and $\mathrm{BF}_{1} / \mathrm{BR}_{1}$ were designed to amplify the $5^{\prime}$-UTR regions of $C g C Y P 51 A$ and $C g C Y P 51 B$, respectively. PCR amplification was performed using the following reaction conditions: initial DNA denaturation at $95^{\circ} \mathrm{C}$ for $5 \mathrm{~min}$; followed by 35 cycles of denaturation $95^{\circ} \mathrm{C}$ for $30 \mathrm{~s}$, annealing at $55^{\circ} \mathrm{C}$ for $40 \mathrm{~s}$, and extension at $72^{\circ} \mathrm{C}$ for $50 \mathrm{~s}$; and final extension at $72^{\circ} \mathrm{C}$ for $7 \mathrm{~min}$. All the amplification products were analyzed by electrophoresis in a $1 \%$ agarose gel with $1 \times$ Tris-acetate EDTA buffer $(0.04 \mathrm{M}$ Tris-acetate and $0.0001 \mathrm{M}$ EDTA) $+2.5 \mathrm{ml}$ of ethidium bromide. All of the PCR products were purified by the USB ExoSAP-IT PCR Product Cleanup Product kit (Affymetrix), and were sequenced by Springen Biotechnology Co., Ltd. Alignment of the sequences was conducted using the software BioEdit V7.0.1 (Manchester, U.K.).

Quantitative expression of $C g C Y P 51 A$ and $C g C Y P 51 B$. Expression of $C g C Y P 51 A$ and $C g C Y P 51 B$ from the eight isolates was assayed according to procedures used by Wang et al. (2015). Briefly, six replicate flasks containing PDB were inoculated with each isolate. After 3 days at $25^{\circ} \mathrm{C}$ in a shaker, tebuconazole was added into three of the six flasks to achieve a final concentration of $10 \mu \mathrm{g} / \mathrm{ml}$ in the flask, and the remaining flasks were used as controls. After

Table 3. Sequences obtained from GenBank used in the analysis

\begin{tabular}{|c|c|c|c|c|}
\hline \multirow[b]{2}{*}{ Species } & \multirow[b]{2}{*}{ Strain } & \multirow[b]{2}{*}{ Reference } & \multicolumn{2}{|c|}{ GenBank accession number ${ }^{\mathrm{z}}$} \\
\hline & & & ITS & TUB \\
\hline Colletotrichum gloeosporioides & $\ldots$ & NCBI & LC052319 & MG448605 \\
\hline C. gloeosporioides & YC11 & This article & $\ldots$ & $\ldots$ \\
\hline C. gloeosporioides & YC78 & This article & $\ldots$ & $\ldots$ \\
\hline C. gloeosporioides & YC2 & This article & $\ldots$ & $\ldots$ \\
\hline C. gloeosporioides & YC18 & This article & $\ldots$ & $\ldots$ \\
\hline C. gloeosporioides & YC22 & This article & $\ldots$ & $\ldots$ \\
\hline C. gloeosporioides & YC44 & This article & $\ldots$ & $\ldots$ \\
\hline C. gloeosporioides & YC56 & This article & $\ldots$ & $\ldots$ \\
\hline C. gloeosporioides & YC61 & This article & $\ldots$ & $\ldots$ \\
\hline C. asianum & BPD-I4 holotype & Prihastuti et al. 2009 & FJ972612 & FJ907439 \\
\hline C. cordylinicola & BCC 38872 holotype & Phoulivong et al. 2011 & HM470246 & HM470249 \\
\hline C. fructicola & BPD-I12 & Prihastuti et al. 2009 & FJ972611 & FJ907440 \\
\hline C. hymenocallidis & CSSN2 holotype & Yang et al. 2009 & GQ485600 & GQ849438 \\
\hline C. musae & CBS116870 epitype & Su et al. 2011 & HQ596292 & HQ596280 \\
\hline C. siamense & BML-I15 & Prihastuti et al. 2009 & FJ972614 & FJ907437 \\
\hline C. viniferum & GZAAS5.08622 & Peng et al. 2013 & JN412806 & JN412812 \\
\hline C. kahawae & IMI319418 holotype & Prihastuti et al. 2009 & FJ972608 & FJ907446 \\
\hline
\end{tabular}

${ }^{\mathrm{z}}$ ITS = partial or complete ribosomal DNA internal transcribed spacer region and TUB = partial $\beta$-tubulin.
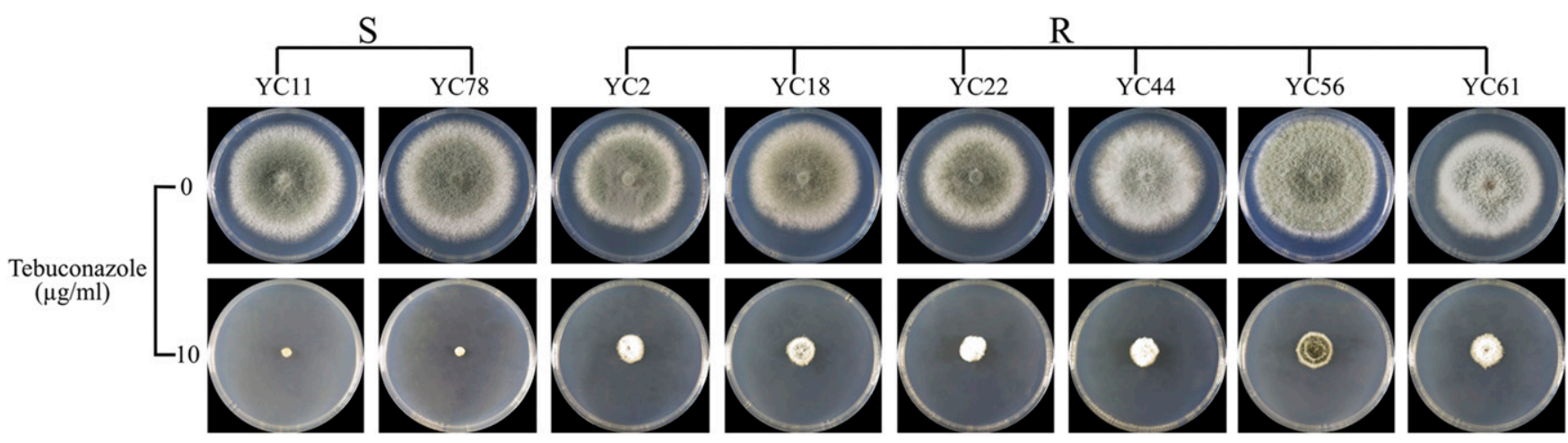

Fig. 2. Mycelia colony growth of the eight isolates (YC11, YC78, YC2, YC18, YC22, YC44, YC56, and YC61) on potato dextrose agar plates with and without tebuconazole. Letters $\mathrm{S}$ and $\mathrm{R}$ indicate sensitive and resistant, respectively. 
$12 \mathrm{~h}$, the mycelia of each isolate were harvested for RNA extraction (Fan et al. 2014). The SV Total RNA Isolation kit (Promega, Beijing, China) was used to extract total RNA, and the PrimeScrip RT reagent Kit with gDNA Eraser (Takara, Beijing, China) was conducted to synthesize cDNA in accordance with the manufacturer's protocol. Reverse-transcription (RT)-PCR was performed with an ABI7500 sequence detection system (Applied Biosystems) to analyze the expression of the two genes with the primer pairs RT-AF/RT-AR and RT-BF/RT-BR (Table 1), respectively. The SYBR Premix Dimer Eraser kit (Takara) was used to amplify the genes. The relative quantities of products were determined by the $2^{-\Delta \Delta \mathrm{Cg}}$ method (Zhang et al. 2017). The $\beta$-tubulin gene was amplified by the primer pair RTTubGF/RT-TubGR as a reference to normalize the quantification of $C g C Y P 51$ expression (Fan et al. 2014). Experiments were conducted with three repetitions.

Molecular docking analysis. Bioinformatic analysis was used to investigate the molecular docking of tebuconazole with the

Table 4. Values of $\mathrm{EC}_{50}$ and $\mathrm{MIC}$ of Colletotrichum gloeosporioides strains against tebuconazole via mycelial growth inhibition method ${ }^{\mathrm{x}}$

\begin{tabular}{llcc}
\hline Strain & Origin $^{\mathbf{y}}$ & $\mathbf{E C}_{\mathbf{5 0}}(\boldsymbol{\mu \mathbf { g }} / \mathbf{m l})^{\mathbf{z}}$ & $\mathbf{M I C}(\boldsymbol{\mu g} / \mathbf{m l})$ \\
\hline YC11 & Field/S & $0.43 \pm 0.02 \mathrm{~d}$ & 10 \\
YC78 & Field/S & $0.49 \pm 0.02 \mathrm{~d}$ & 10 \\
YC2 & Field/R & $0.74 \pm 0.03 \mathrm{~b}$ & 60 \\
YC18 & Field/R & $0.76 \pm 0.02 \mathrm{~b}$ & 60 \\
YC22 & Field/R & $0.61 \pm 0.02 \mathrm{c}$ & 60 \\
YC44 & Field/R & $0.74 \pm 0.03 \mathrm{~b}$ & 60 \\
YC56 & Field/R & $0.77 \pm 0.04 \mathrm{~b}$ & 90 \\
YC61 & Field/R & $1.42 \pm 0.09 \mathrm{a}$ & 70 \\
\hline
\end{tabular}

${ }^{\mathrm{x}} \mathrm{EC}_{50}=$ effective concentration for $50 \%$ inhibition of mycelial growth and MIC $=$ minimum inhibitive concentration for $100 \%$ inhibition of mycelia growth.

y $\mathrm{S}=$ sensitive and $\mathrm{R}=$ resistant.

$\mathrm{z}$ Values in each column followed by the same letter for each treatment are not significantly different at $P=0.05$.
CgCYP51 proteins; the complete amino acid sequences of CgCYP51A and CgCYP51B from the sensitive and resistant isolates were used to search for suitable models on the online Swiss-model platform (https://www.swissmodel.expasy.org/interactive). The two crystal structures of 4uyl.2.A and 4uyl.1.A of CYP51B from Aspergillus fumigatus showed 59.70 and $55.94 \%$ identity with the amino acid sequences of CgCYP51A and CgCYP51B, respectively. The binding cavity was predicted by a ligand mode for tebuconazole complexed in CYP51 with SYBYL 2.0 software. The Tripos force field with Gasteiger-Marsili charges was used for the energy minimization. The molecular conformation of tebuconazole was established by Sketch mode, and was optimized by the Tripos force field and Gasteiger-Hückel charge. The binding cavity was set up as "ligand", and the docking total scores (DTSs) were used to assess the binding affinity between ligand and protein.

Statistical analysis. Data Processing System software (V7.05; Hangzhou, China) was used to process all data. Statistical significance was determined by the Duncan test and least significant difference test at $P=0.05$. Cross-resistance between two fungicides was determined by Spearman's rank correlation coefficient with logtransformed $\mathrm{EC}_{50}$ values (Spolti et al. 2014).

\section{Results}

Determination the sensitivity of all isolates to tebuconazole. Of the 48 isolates collected from commercial chili fields, 8 single-spore isolates were identified as $C$. gloeosporioides by sequencing and BLAST analysis of the conserved ITS and $\beta$-tubulin (Fig. 1; Table 3). The rest of the isolates were identified as $C$. acutatum (data not show). Six of eight $C$. gloeosporioides isolates could grow on PDA plates amended with tebuconazole at $10 \mu \mathrm{g} / \mathrm{ml}$ and two could not grow (Fig. 2), which indicated that six isolates were resistant to tebuconazole and the tebuconazole resistance of $C$. gloeosporioides had developed in the fields. All of the $C$. acutatum isolates were sensitive to tebuconazole based on the mycelia growth inhibition bioassay, suggesting that tebuconazole resistance of $C$. acutatum had not developed. Furthermore, the resistant mechanism of C. gloeosporioides to tebuconazole was studied; $\mathrm{EC}_{50}$ values of $C$.
A Control

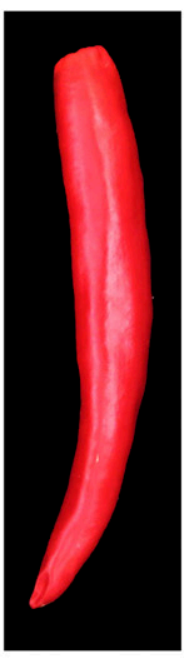

B Control

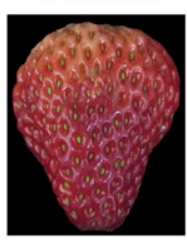

YC11
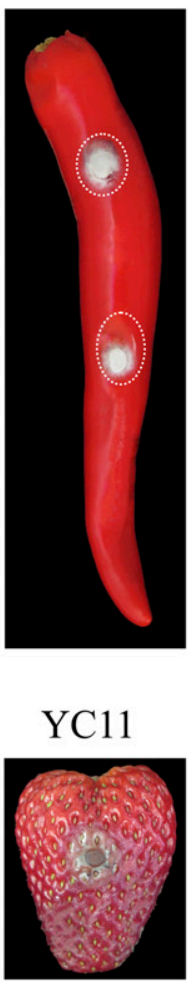

YC78
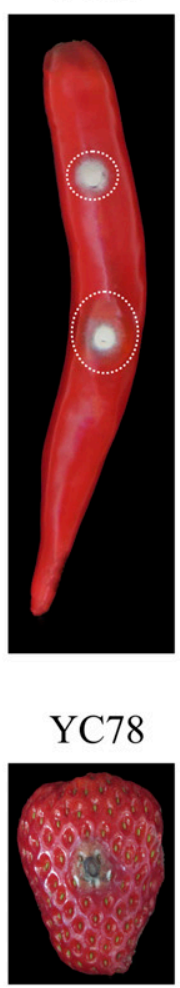

$\mathrm{YC} 2$
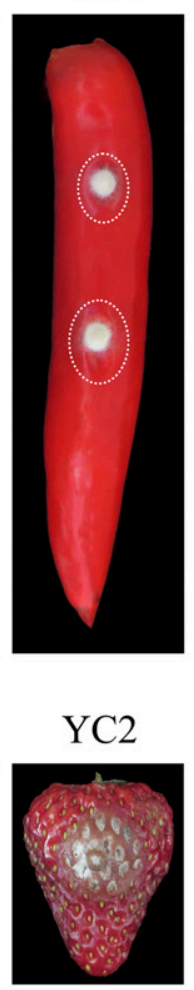

$\mathrm{YC} 18$
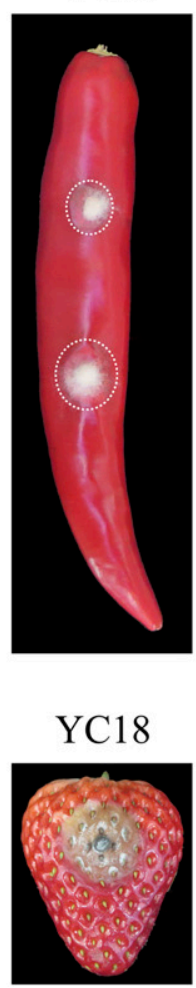

YC22

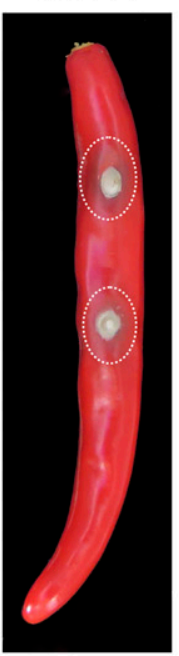

YC22

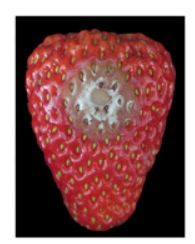

YC44
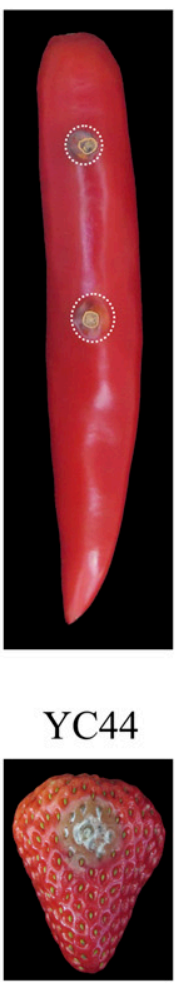
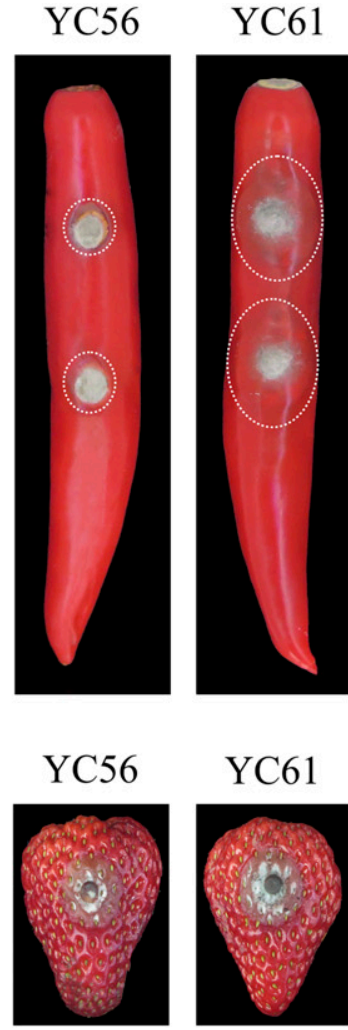

Fig. 3. Virulence analysis of the eight isolates by inoculation on mature fruit of $\mathbf{A}$, chili and $\mathbf{B}$, strawberry. Disease symptoms were investigated at 5 days postinoculation. 
gloeosporioides-resistant isolates were approximately 0.50 - to 2.30 fold higher than sensitive isolates, while the minimum inhibitive concentration for $100 \%$ inhibition of mycelia growth values were approximately 5.00 - to 8.00 -fold higher than the sensitive isolates, indicating that the six isolates were moderately resistant to tebuconazole (Table 4).

Mycelia growth, sporulation, spore-germination rate, and pathogenicity. Mycelial growth rates of resistant isolates (except YC56) were significantly slower than the sensitive isolates $(P=$ $0.05)$. Of the six resistant isolates, four exhibited significantly stronger sporulation than the sensitive isolates $(P=0.05)$. Additionally, all of the resistant isolates differed significantly in sporegermination rates, and the pathogenicity on mature fruits of chili (Fig. 3A) and strawberry (Fig. 3B). In brief, not all of the resistant isolates exhibited the decreased mycelia growth rate, sporulation, and pathogenicity (Table 5).

Cross-resistance. Cross-resistance was observed between tebuconazole and difenoconazole $(r=0.8333,0.005<P<0.01)$ or propiconazole $(r=0.7857,0.01<P<0.025)$. However, there was no cross-resistance between tebuconazole and prochloraz $(r=0.5000$,

Table 5. Comparison of mycelia growth, sporulation, virulence and conidia germination rate among the tebuconazole-resistant and -sensitive strains of $C$ olletotrichum gloeosporioides ${ }^{\mathrm{u}}$

\begin{tabular}{|c|c|c|c|c|c|c|}
\hline \multirow[b]{2}{*}{ Strain } & \multirow[b]{2}{*}{ Origin $^{w}$} & \multirow[b]{2}{*}{ Growth $(\mathbf{m m})^{\mathrm{x}}$} & \multirow[b]{2}{*}{ Conid $\left(\times 10^{6}\right)^{y}$} & \multirow[b]{2}{*}{ Rate $(\%)^{\mathbf{z}}$} & \multicolumn{2}{|c|}{ Virulence (lesion diameter $[\mathrm{mm}])^{\mathrm{v}}$} \\
\hline & & & & & Chili & Strawberry \\
\hline YC11 & Field/S & $72.00 \pm 2.85 b$ & $17.62 \pm 5.47 \mathrm{~d}$ & $94.83 \pm 1.03 \mathrm{ab}$ & $10.56 \pm 1.24 \mathrm{cde}$ & $15.50 \pm 0.89 c$ \\
\hline YC78 & Field/S & $76.50 \pm 0.85 a$ & $15.40 \pm 2.52 \mathrm{de}$ & $88.67 \pm 5.75 \mathrm{bc}$ & $12.33 \pm 1.19 \mathrm{bc}$ & $14.25 \pm 0.29 \mathrm{c}$ \\
\hline YC 2 & Field/R & $65.00 \pm 0.45 \mathrm{c}$ & $70.21 \pm 15.42 b$ & $81.50 \pm 3.49 \mathrm{~cd}$ & $11.67 \pm 1.30 \mathrm{bcd}$ & $19.75 \pm 0.29 \mathrm{ab}$ \\
\hline YC18 & Field/R & $65.00 \pm 0.77 \mathrm{c}$ & $36.94 \pm 13.09 \mathrm{c}$ & $50.33 \pm 3.36 \mathrm{f}$ & $10.00 \pm 0.60 \mathrm{de}$ & $19.75 \pm 0.29 \mathrm{ab}$ \\
\hline YC22 & Field/R & $67.00 \pm 1.55 \mathrm{c}$ & $47.79 \pm 3.59 c$ & $62.83 \pm 1.29 \mathrm{e}$ & $13.83 \pm 1.81 \mathrm{~b}$ & $22.25 \pm 2.02 \mathrm{a}$ \\
\hline YC44 & Field/R & $61.25 \pm 1.16 \mathrm{~d}$ & $91.10 \pm 3.13 \mathrm{a}$ & $87.83 \pm 6.27 \mathrm{bcd}$ & $9.00 \pm 0.89 \mathrm{e}$ & $20.50 \pm 1.15 \mathrm{ab}$ \\
\hline YC56 & Field/R & $76.00 \pm 0.45 \mathrm{a}$ & $1.10 \pm 0.92 \mathrm{e}$ & $100.00 \pm 0 \mathrm{a}$ & $9.33 \pm 0.30 \mathrm{e}$ & $19.00 \pm 0.58 b$ \\
\hline YC61 & Field/R & $66.83 \pm 0.26 c$ & $3.95 \pm 0.25 \mathrm{de}$ & $80.17 \pm 4.74 \mathrm{~d}$ & $20.25 \pm 0.59 \mathrm{a}$ & $18.50 \pm 0 \mathrm{~b}$ \\
\hline
\end{tabular}

u Values in each column followed by the same letter for each treatment are not significantly different at $P=0.05$.

${ }^{v}$ Lesion diameters were determined on chili and strawberry in vivo after inoculation for 5 days.

${ }^{\mathrm{w}} \mathrm{S}=$ sensitive and $\mathrm{R}=$ resistant.

${ }^{x}$ Mycelia growth was measured after inoculation at $25^{\circ} \mathrm{C}$ for 5 days on fungicide-free potato dextrose agar plates.

y Conidiation: conidia $\left(\times 10^{6}\right.$ conidium $\left./ \mathrm{ml}\right)$ produced on alkyl ester agar medium 7 days after inoculation.

$\mathrm{z}$ Conidia germination rate was measured after inoculation at $25^{\circ} \mathrm{C}$ for $4 \mathrm{~h}$.

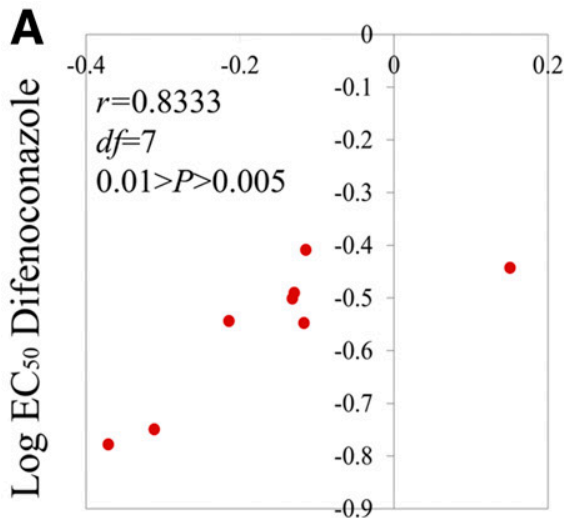

Log $\mathrm{EC}_{50}$ Tebuconazole

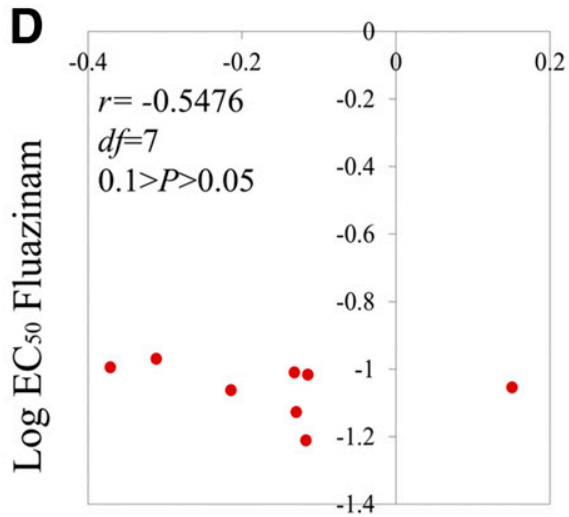

Log $\mathrm{EC}_{50}$ Tebuconazole
B

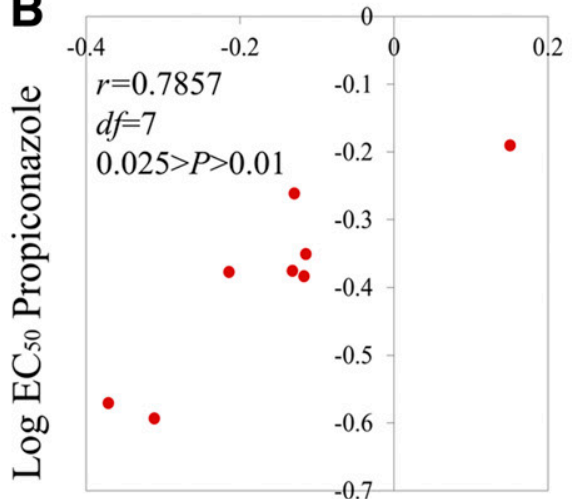

Log EC 50 Tebuconazole

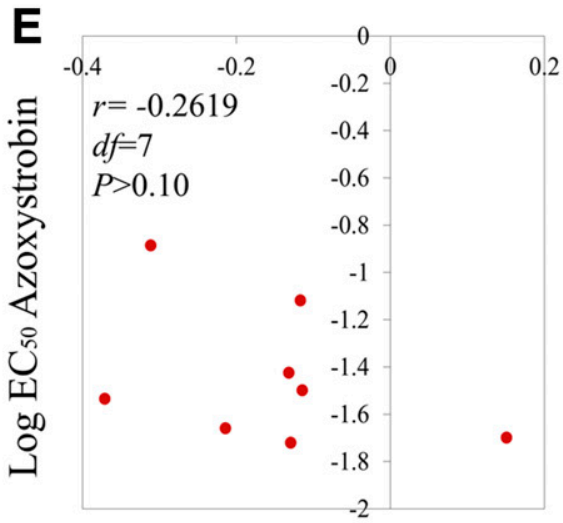

Log $\mathrm{EC}_{50}$ Tebuconazole

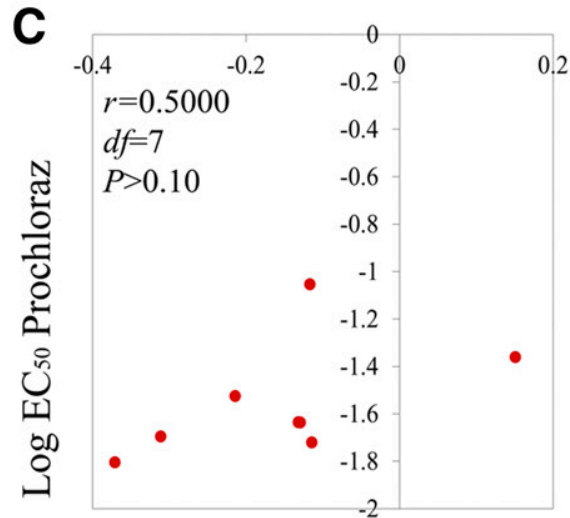

$\log \mathrm{EC}_{50}$ Tebuconazole

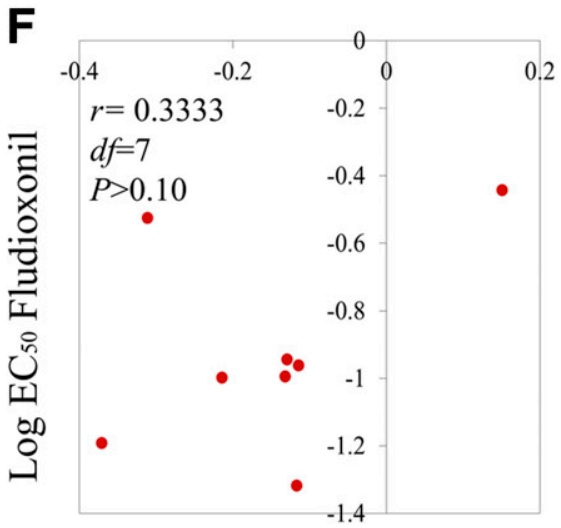

Log $\mathrm{EC}_{50}$ Tebuconazole

Fig. 4. Spearman rank correlation for cross-resistance in chili (pepper) anthracnose between tebuconazole and six other fungicides, including A, difenoconazole; $\mathbf{B}$, propiconazole; C, prochloraz; D, fluazinam; E, azoxystrobin; and F, fludioxonil. Data points are the logarithmic values of effective concentrations for $50 \%$ mycelia growth inhibition (log $\mathrm{EC}_{50}$ ) among the tested isolates for the indicated fungicide combinations. 
$P>0.10)$, fluazinam $(r=-0.5476,0.05<P<0.1)$, azoxystrobin $(r=$ $-0.2619, P>0.1)$, or fludioxonil $(r=0.3333, P>0.1)$ (Fig. 4).

Sequence alignment of $C g C Y P 51 A$ and $C g C Y P 51 B$ of sensitive and resistant isolates. Mutations at amino acid codons are conferred for the resistance against DMIs (Leroux et al. 2007; Mellado et al. 2007). To explore the genetic mechanism of $C$. gloeosporioides resistance to tebuconazole, all of the 5'-UTRs and the whole open reading frames of $C g C Y P 51 A$ and $C g C Y P 51 B$ from the eight isolates were analyzed. Based on the alignment, mutations occurred at $C g C Y P 51 A$ or $C g C Y P 51 B$ (Table 6). All of the mutations were categorized into three resistant genotypes. Genotype I possessed four point mutations (V18L, L58V, S175P, and P341A) at $C g C Y P 51 A$ but no mutation at $C g C Y P 51 B$, whereas genotype II had five point mutations (L58V, S175P, A340S, T379A, and N476T) at CgCYP51A, concomitant with three point mutations (D121N, $\mathrm{T} 132 \mathrm{~A}$, and $\mathrm{F} 391 \mathrm{Y})$ at $C g C Y P 51 B$. Additionally, genotype III contained two point mutations (L58V and S175P) at $C g C Y P 51 A$, concomitant with one point mutation (T262A) at $C g C Y P 51 B$. No mutations or insertions were observed in the 5'-UTRs of $C g C Y P 51 A$ or $C g C Y P 51 B$ from the six resistant isolates.

Overexpression of $C g C Y P 51 A$ and $C g C Y P 51 B$ genes. Overexpression of fungal CYP51 genes has been reported to be involved in the resistance of phytopathogenic fungi to DMIs (Nikou et al. 2009; Schnabel and Jones 2001). Expression of CgCYP51 genes of the sensitive isolates was slightly increased by 0.28 - to 0.50 -fold in $C g C Y P 51 A$ and 0.28 to 1.00 -fold in $C g C Y P 51 B$; meanwhile, expression of $C g C Y P 51$ genes of resistant isolates significantly increased 2.00 - to 21.00 -fold in $C g C Y P 51 A$ and 1.00 - to 14.00 -fold in $C g C Y P 51 B$ under the same conditions. Of the three resistant

Table 6. Comparison of the amino acid sequences of genes $\mathrm{CgCYP51A}$ and CgCYP51B among the tebuconazole-resistant and -sensitive strains of Colletotrichum gloeosporioides

\begin{tabular}{lcccc}
\hline & & \multicolumn{2}{c}{ Mutated sites } \\
\cline { 4 - 5 } Strain & Origin $^{z}$ & Genotype & CgCYP51A & CgCYP51B \\
\hline YC11, YC78 & Field/S & $\ldots$ & $\ldots$ & $\ldots$ \\
YC2, YC18, & Field/R & I & V18F, L58V, & $\ldots$ \\
YC22, YC44 & & & S175P, and & \\
& & & P341A & \\
YC56 & Field/R & II & L58V, S175P, & D121N, T132A, \\
& & & A340S, T379A & and F391Y \\
& & & and N476T & \\
YC61 & Field/R & III & L58V and S175P & T262A \\
\hline
\end{tabular}

${ }^{\mathrm{z}} \mathrm{S}=$ sensitive and $\mathrm{R}=$ resistant.

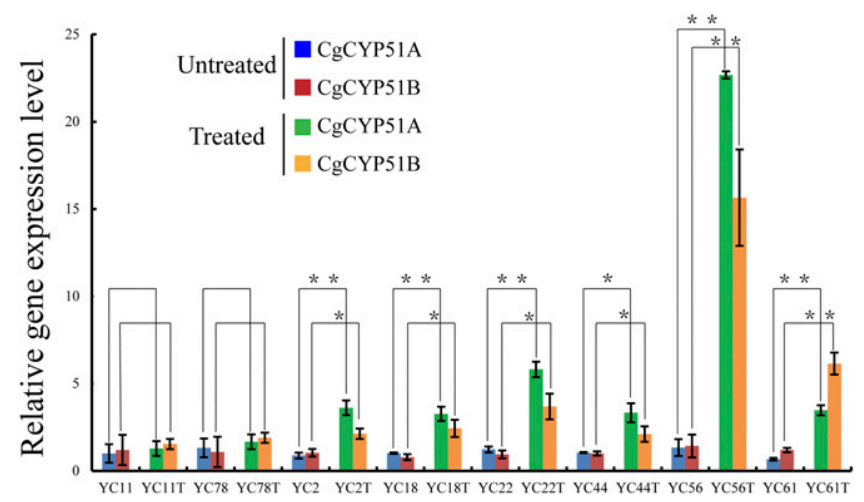

Fig. 5. Expression of CgCYP51A and CgCYP51B in the sensitive and resistant isolates of Colletotrichum gloeosporioides. Mycelia of each isolate was treated with tebuconazole at 0 or $10 \mu \mathrm{g} / \mathrm{ml}$ for $12 \mathrm{~h}$ after growth in potato dextrose broth for $24 \mathrm{~h}$. Bars denote standard errors from three repeated experiments. An asterisk indicates significantly different from the control. genotypes, the expression of $C g C Y P 51$ genes of the resistant genotype II was significantly higher than the other two resistant genotypes (Fig. 5).

Analysis of the affinity between CgCYP51 proteins and tebuconazole. Models were established for the docking of tebuconazole into the CgCYP51A or CgCYP51B protein-binding pocket (Fig. 6). In addition, the $\mathrm{CgCYP} 51 \mathrm{~A}$ and $\mathrm{CgCYP} 51 \mathrm{~B}$ proteins of the sensitive isolate (YC11 or YC78) were docked as references. The docking of CgCYP51A protein with tebuconazole showed that five hydrogen bonds could be formed between tebuconazole and the amino acids Y128 and K139 in the wild type or resistant genotype I, while five or six hydrogen bonds were formed between tebuconazole and the amino acids Y128, K139, and H454 in the resistant genotype III or II, respectively (Fig. 6A). Meanwhile, the docking of CgCYP51B protein with tebuconazole indicated that three hydrogen bonds were formed between tebuconazole and amino acids R136 and H467, R110 and H309, or R136 and R377 in the wild type, resistant genotype II, or resistant genotype III, respectively (Fig. 6B). The DTSs of the three resistant genotypes were lower than that of the sensitive isolate (Table 7), indicating that the affinity between tebuconazole and $\mathrm{CgCYP} 51 \mathrm{~A}$ or CgCYP51B proteins was decreased in the resistant isolates.

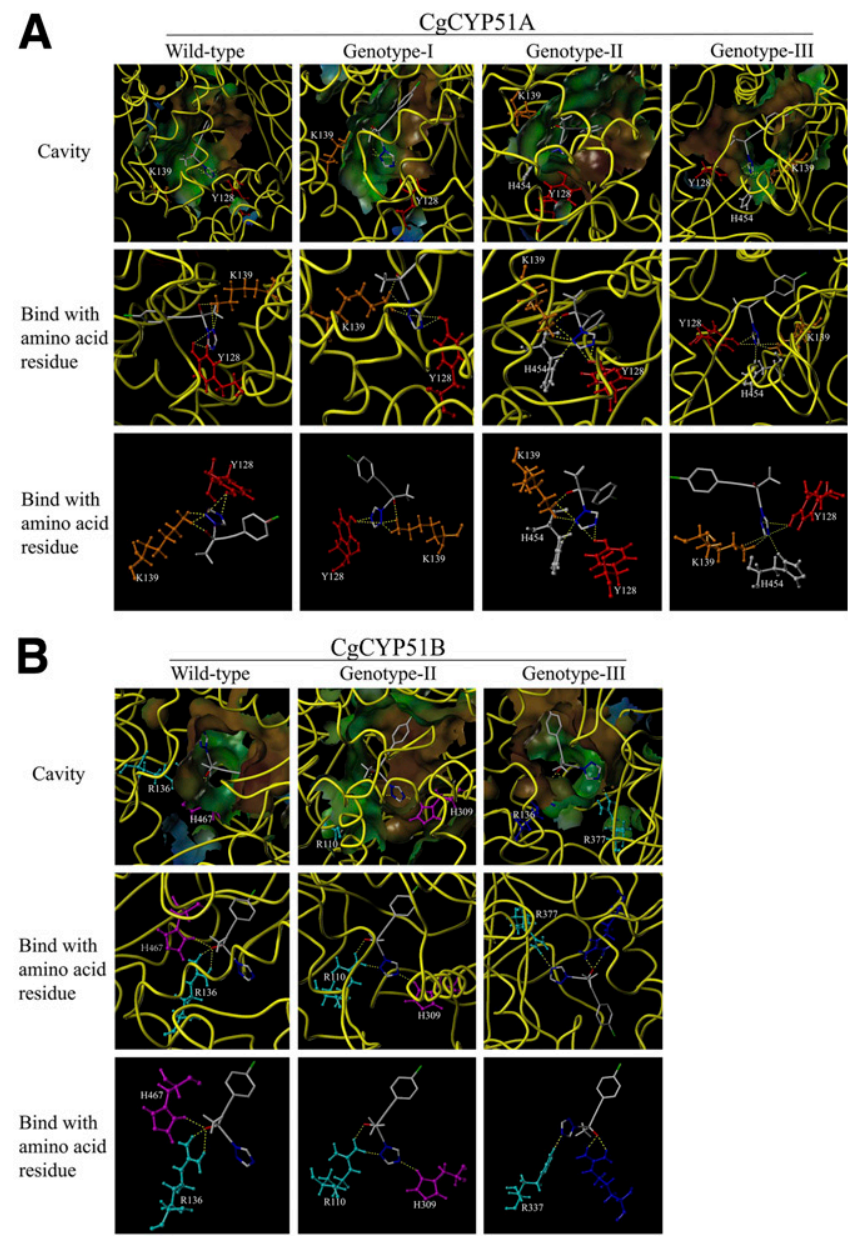

Fig. 6. Molecular docking of tebuconazole with the protein CgCYP51 of Colletotrichum gloeosporioides. Modeling structures of the $\mathrm{CgCYP} 51 \mathrm{~A}(\mathrm{~A})$ and $\mathrm{CgCYP} 51 \mathrm{~B}$ (B) protein domains from $C$. gloeosporioides were obtained by using the templates 4uyl.2.A and 4uyl.1.A, two CYP51B proteins from the Aspergillus fumigatus, and the online Swiss-model platform (https://swissmodel.expasy.org/). Binding cavities were predicted by a ligand mode for tebuconazole complexed in CgCYP51 by SYBYL 2.0 software. The Tripos force field with Gasteiger-Hückel charges was used to minimize the energy. The molecular conformation of tebuconazole was constructed by Sketch mode and was optimized using the Tripos force field and Gasteiger-Hückel charge. 


\section{Discussion}

Resistance of Colletotrichum spp. isolated from chili to benzimidazole derivatives has been documented in China since 2002 (Li et al. 2002). Owing to the specific mode of action, DMIs have become a crucial component of successful resistance management strategies to control anthracnose of chili in Jiangsu Province of China for more than three decades. However, the DMI resistance of Colletotrichum spp. has been reported in recent years (Chen et al. 2013; Chen et al. 2016). Although C. gloeosporioides and C. acutatum were isolated from chili fruit with typical lesions, only one of the two species was isolated from a single lesion, suggesting that one lesion is not often caused by the two combined Colletotrichum spp. in field. In addition, moderately resistant isolates with mutations at $C g C Y P 51 A$ or $C g C Y P 51 B$ were selected in the field, and each resistant isolate had low fitness cost, most likely due to fast selection. This scenario is similar to the mixed populations of Fusarium graminearum and $F$. asiaticum selected by benzimidazole derivatives in field (Chen et al. 2009; Qu et al. 2008). To our knowledge, this is the first report that mutations at $C g C Y P 51 A$ or $C g C Y P 51 B$ are involved in the resistance of $C$. gloeosporioides against DMIs.

Mutations at $C g C Y P 51 A$ or $C g C Y P 51 B$ in $C$. gloeosporioides are related to the resistance against DMIs. The first and only case related to resistance of $C$. gloeosporioides against prochloraz from mango was reported in 2003 (Gutiérrez Alonso et al. 2003). However, in the two other Colletotrichum spp. including C. truncatum, resistant to tebuconazole, metconazole, flutriafol, and fenbuconazole, and C. nymphaeae, resistant to flutriafol and fenbuconazole, from peach orchards in 2016, the point mutations at CYP51A and CYP51B from resistant isolates were associated with resistance to DMIs (Chen et al. 2016). CYP51 genes are widely distributed in all biological kingdoms, including fungi, plants, bacteria, and animals (Doddapaneni et al. 2005). However, the number of CYP51 genes varies in fungi. Unlike only a single $C Y P 51$ gene in Hemiascomycete yeasts and basidiomycetes, Pezizomycotina, a subphylum of the phylum Ascomycota, contains many phytopathogenic and clinical fungi, and has two or three copies of the CYP51 genes (Fan et al. 2013). Although some filamentous fungi possess more than one copy of a CYP51 gene, mutations at $C Y P 51$ commonly occur at CYP51A of phytopathogenic fungi to confer DMI resistance, and rarely occur at $C Y P 51 B$ or CYP51A and B (Délye et al. 1998). The results in clinical fungi, with an exception for $A$. clavatus, are similar to those in phytopathogenic fungi (Song et al. 2018). In A. clavatus, point mutations at CYP51A and $C Y P 51 B$ genes are involved in posaconazole and itraconazole resistance (Abastabar et al. 2019). In brief, the result in the study was similar to that in A. clavatus, C. truncatum, and C. nymphaeae.

Overexpression of $C g C Y P 51 A$ and $C g C Y P 51 B$ of resistant isolates was observed in response to tebuconazole. In the current study, both CgCYP51A and CgCYP51B genes from C. gloeosporioides overexpressed when treated with tebuconazole at $10 \mu \mathrm{g} / \mathrm{ml}$ for $12 \mathrm{~h}$. To date, overexpression of CYP51 genes caused by promoter insertions or retrotransposons are reported in only a few phytopathogenic fungi; for example, a duplication of a 65-bp sequence was found at a promoter of CYP51 of Monilinia fructicola (Luo and Schnabel 2008), and a 2- to 5-kb retrotransposon was found at Blumeriella jaapii (Ma et al. 2006). However, mechanisms underlying overexpression of CYP51 are not known in the field for DMI-resistant subpopulations

Table 7. Docking total scores (DTSs) of the fungicide tebuconazole into the Colletotrichum gloeosporioides CYP51 protein binding pockets of sensitive or resistant mutants

\begin{tabular}{lcccc}
\hline & & & \multicolumn{2}{c}{ DTSs } \\
\cline { 4 - 5 } Strain & Origin $^{z}$ & Genotype & CYP51A & CYP51B \\
\hline YC11, YC78 & Field/S & $\ldots$ & 3.2366 & 2.9772 \\
YC2, YC18, YC22, YC44 & Field/R & I & 2.3081 & $\ldots$ \\
YC56 & Field/R & II & 3.1512 & 1.5772 \\
YC61 & Field/R & III & 1.7003 & 1.4701 \\
\hline z S = sensitive and R = resistant. & & &
\end{tabular}

${ }^{\mathrm{z}} \mathrm{S}=$ sensitive and $\mathrm{R}=$ resistant. of Cercospora beticola (Bolton et al. 2012), Phakopsora pachyrhizi (Schmitz et al. 2014), Puccinia triticina (Stammler et al. 2009), and Sclerotinia homeocarpa (Hulvey et al. 2012). In current study, the molecular mechanism of CYP51 overexpression needs further investigation.

Knowledge of fitness costs is crucial for predicting effectiveness and optimizing disease control strategies based on fungicide combinations (Mikaberidze and McDonald 2015). The results of fitness comparison indicated that the resistant genotype I exhibited decreased rates of mycelia growth and spore germination, increased sporulation, and similar pathogenicity when compared with the sensitive isolates. Because only one isolate of the resistant genotype II or III was available, we will look for more isolates with those resistant genotypes in future to characterize their specific fitness parameters. Furthermore, positive cross-resistance was observed between tebuconazole and difenoconazole but not between tebuconazole and prochloraz. The reason no cross-resistance between tebuconazole and prochloraz was observed in the current study possibly resulted from the fact that prochloraz chemically belongs to an imidazole fungicide, which is very different from tebuconazole and difenoconazole, two triazole fungicides. The lack of cross-resistance between different fungicides with different modes of action in the study such as fluazinam, azoxystrobin, and fludioxonil can be used to manage the DMI resistance of Colletotrichum gloeosporioides. In addition, fungicides with high or low resistance risk-such as azoxystrobin and fluazinam or fludioxonil, prochloraz, and fluazinam or fludioxonil, and so on-could be used together to delay the resistance development of $C$. gloeosporioides in fields. Furthermore, rational use of fungicides serves as an important component of an integrated antiresistance management strategy.

In brief, the moderate resistance of $C$. gloeosporioides to DMIs has developed in the chili fields in Jiangsu Province of China. Mutations at $C g C Y P 51 A$ or $C g C Y P 51 B$ are involved in the resistance to tebuconazole. All of the resistant isolates possessed a low fitness penalty. Prochloraz and other fungicides with different modes of action should be integrated into disease management programs to reduce fungicide resistance development.

\section{Literature Cited}

Abastabar, M., Hosseini, T., Valadan, R., Lagzian, M., Haghani, I., Aslani, N., Badali, H., Nouripour-Sisakht, S., Nazeri, M., and Gholami, S. 2019. Novel point mutations in cyp51A and cyp51B genes associated with itraconazole and posaconazole resistance in Aspergillus clavatus isolates. Microb. Drug Resist. 25.

Bolton, M. D., Birla, K., Rivera-Varas, V., Rudolph, K. D., and Secor, G. A. 2012. Characterization of CbCyp51 from field isolates of Cercospora beticola. Phytopathology 102:298-305

Cañas-Gutiérrez, G. P., Angarita-Velásquez, M. J., Restrepo-Flórez, J. M. Rodríguez, P., Moreno, C. X., and Arango, R. 2009. Analysis of the CYP51 gene and encoded protein in propiconazole-resistant isolates of Mycosphaerella fijiensis. Pest Manage. Sci. 65:892-899.

Cao, X., Xu, X., Che, H., West, J. S., and Luo, D. 2017. Distribution and fungicide sensitivity of Colletotrichum species complexes from rubber tree in Hainan, China. Plant Dis. 101:1774-1780.

Chen, C.-J., Yu, J.-J., Bi, C.-W., Zhang, Y.-N., Xu, J.-Q., Wang, J.-X., and Zhou, M.-G. 2009. Mutations in a $\beta$-tubulin confer resistance of Gibberella zeae to benzimidazole fungicides. Phytopathology 99:1403-1411.

Chen, D., Shi, H. J., Hui-Ming, W. U., Zhi-Hong, X. U., and Zhang, C. Q. 2013. Resistance of Colletotrichum gloeosporioides causing grape ripe rot to thiophanate-methyl and tebuconazole in Zhejiang. J. Fruit Sci. 30:665-668.

Chen, J., Li, H., Li, R., Bu, D., and Wan, Z. 2005. Mutations in the cyp51A gene and susceptibility to itraconazole in Aspergillus fumigatus serially isolated from a patient with lung aspergilloma. J. Antimicrob. Chemother. 55:31-37.

Chen, S., Luo, C., Hu, M., and Schnabel, G. 2016. Characterization of resistance to DMI fungicides in Colletotrichum spp. isolates from peach. (Abstr.) Phytopathology 106:S4.71.

Chowdhary, A., Kathuria, S., Randhawa, H. S., Gaur, S. N., Klaassen, C. H., and Meis, J. F. 2012. Isolation of multiple-triazole-resistant Aspergillus fumigatus strains carrying the TR/L98H mutations in the cyp51A gene in India. J. Antimicrob. Chemother. 67:362-366.

Davidse, L. C. 1986. Benzimidazole fungicides: Mechanism of action and biological impact. Annu. Rev. Phytopathol. 24:43-65.

Délye, C., Bousset, L., and Corio-Costet, M. F. 1998. PCR cloning and detection of point mutations in the eburicol 14a-demethylase (CYP51) gene from Erysiphe graminis f. sp. hordei, a "recalcitrant" fungus. Curr. Genet. 34:399-403. 
Délye, C., Laigret, F., and Corio-Costet, M.-F. 1997. A mutation in the 14 alphademethylase gene of Uncinula necator that correlates with resistance to a sterol biosynthesis inhibitor. Appl. Environ. Microbiol. 63:2966-2970.

Doddapaneni, H., Chakraborty, R., and Yadav, J. S. 2005. Genome-wide structural and evolutionary analysis of the P450 monooxygenase genes (P450ome) in the white rot fungus Phanerochaete chrysosporium: Evidence for gene duplications and extensive gene clustering. BMC Genomics 6:92.

Fan, J., Chen, F., Diao, Y., Cools, H. J., Kelly, S. L., and Liu, X. 2014. The Y123H substitution perturbs FvCYP51B function and confers prochloraz resistance in laboratory mutants of Fusarium verticillioides. Plant Pathol. 63:952-960.

Fan, J., Urban, M., Parker, J. E., Brewer, H. C., Kelly, S. L., Hammond-Kosack, K. E., Fraaije, B. A., Liu, X., and Cools, H. J. 2013. Characterization of the sterol $14 \alpha$-demethylases of Fusarium graminearum identifies a novel genusspecific CYP51 function. New Phytol. 198:821-835.

Gao, Y., He, L., Li, B., Lin, J., Mu, W., and Liu, F. 2017. Identification of the pathogen causing pepper anthracnose in Shandong Province and screening of highly effective fungicides. Sci. Agric. Sin. 50:1452-1464.

Gisi, U., and Sierotzki, H. 2008. Fungicide modes of action and resistance in downy mildews. Eur. J. Plant Pathol. 122:157-167.

Gutiérrez Alonso, J. G., Gutiérrez Alonso, O., Nieto Ángel, D., Téliz Ortiz, D., Zavaleta Mejía, E., Delgadillo Sánchez, F., and Vaquera Huerta, H. 2003. Resistencia a benomil y tiabendazol en aislamientos de Colletotrichum gloeosporioides (Penz.) Penz. y Sacc. obtenidos de mango (Mangifera indica L.) en cinco regiones de México. Rev. Mex. Fitopatol. 21:260-266.

Hamamoto, H., Hasegawa, K., Nakaune, R., Lee, Y. J., Makizumi, Y., Akutsu, K., and Hibi, T. 2000. Tandem repeat of a transcriptional enhancer upstream of the sterol 14 $\alpha$-demethylase gene (CYP51) in Penicillium digitatum. Appl. Environ. Microbiol. 66:3421-3426.

Harp, T., Kuhn, P., Roberts, P. D., and Pernezny, K. L. 2013. Management and cross-infectivity potential of Colletotrichum acutatum causing anthracnose on bell pepper in Florida. Phytoparasitica 42:31-39.

Hulvey, J., Popko, J. T., Sang, H., Berg, A., and Jung, G. 2012. Overexpression of ShCYP51B and ShatrD in Sclerotinia homoeocarpa isolates exhibiting practical field resistance to a demethylation inhibitor fungicide. Appl. Environ. Microbiol. 78:6674-6682.

Ishii, H., Zhen, F., Hu, M., Li, X., and Schnabel, G. 2016. Efficacy of SDHI fungicides including benzovindiflupyr against Colletotrichum species. Pest Manage. Sci. 72:1844-1853.

Ivic, D., Voncina, D., Sever, Z., Simon, S., and Pejic, I. 2013. Identification of Colletotrichum species causing bitter rot of apple and pear in Croatia. J. Phytopathol. 161:284-286.

Jang, M. H., Yong, S. M., Noh, J. H., Kim, S. H., Hong, S. K., and Yun, H. K. 2011. In vitro evaluation system for varietal resistance against ripe rot caused by Colletotrichum acutatum in grapevines. Hortic. Environ. Biotechnol. 52:52-57.

Lamsal, K., Sang, W. K., Yun, S. K., and Lee, Y. S. 2012. Application of rhizobacteria for plant growth promotion effect and biocontrol of anthracnose caused by Colletotrichum acutatum on pepper. Mycobiology 40:244-251.

Leadbeater, A., and Thind, T. S. 2012. Resistance risk to QoI fungicides and antiresistance strategies. Pages 141-156 in: Fungicide Resistance in Crop Protection: Risk and Management. T. S. Thind, ed. CABI, Wallingford, U.K.

Leroux, P., Albertini, C., Gautier, A., Gredt, M., and Walker, A. S. 2007. Mutations in the CYP51 gene correlated with changes in sensitivity to sterol $14 \alpha$-demethylation inhibitors in field isolates of Mycosphaerella graminicola. Pest Manage. Sci. 63:688-698.

Lewis Ivey, M. L., Nava-Diaz, C., and Miller, S. A. 2004. Identification and management of Colletotrichum acutatum on immature bell peppers. Plant Dis. 88:1198-1204.

Li, H., Lu, Y., Wang, J., and Zhou, M. 2002. Comparison of mutations in the $\beta$-tubulin gene that confer resistance to carbendazim in four plant pathogenic fungi. J. Nanjing Agric. Univ. 25:41-44.

Li, H.-X., Liu, Z.-Y., Wang, J.-X., and Zhou, M.-G. 2005. Baseline sensitivity of Colletotrichum gloeosporioides and $C$. capsici from capsium to azoxystrobin. Acta Phytopathol. Sin. 35:73-77.

Liao, C.-Y., Chen, M.-Y., Chen, Y.-K., Wang, T.-C., Sheu, Z.-M., Kuo, K.-C., Chang, P.-F. L., Chung, K.-R., and Lee, M.-H. 2012. Characterization of three Colletotrichum acutatum isolates from Capsicum spp. Eur. J. Plant Pathol. 133.599-608.

Lin, T., Xu, X. F., Dai, D. J., Shi, H. J., Wang, H. D., and Zhang, C. Q. 2016. Differentiation in development of benzimidazole resistance in Colletotrichum gloeosporioides complex populations from strawberry and grape hosts. Australas. Plant Pathol. 45:241-249.

Luo, C.-X., and Schnabel, G. 2008. The cytochrome P450 lanosterol $14 \alpha-$ demethylase gene is a demethylation inhibitor fungicide resistance determinant in Monilinia fructicola field isolates from Georgia. Appl. Environ. Microbiol. 74:359-366.

Ma, Z., Proffer, T. J., Jacobs, J. L., and Sundin, G. W. 2006. Overexpression of the $14 \alpha$-demethylase target gene (CYP51) mediates fungicide resistance in Blumeriella jaapii. Appl. Environ. Microbiol. 72:2581-2585.

Mann, P. A., Parmegiani, R. M., Shui-Qing, W., Mendrick, C. A., Xin, L., David, L., Beth, D. D., Hare, R. S., Walker, S. S., and Mcnicholas, P. M. 2003. Mutations in Aspergillus fumigatus resulting in reduced susceptibility to posaconazole appear to be restricted to a single amino acid in the cytochrome P450 14alpha-demethylase. Antimicrob. Agents Chemother. 47:577-581.
Mellado, E., Garcia-Effron, G., Alcazar-Fuoli, L., Melchers, W., Verweij, P., Cuenca-Estrella, M., and Rodriguez-Tudela, J. 2007. A new Aspergillus fumigatus resistance mechanism conferring in vitro cross-resistance to azole antifungals involves a combination of cyp51A alterations. Antimicrob. Agents Chemother. 51:1897-1904

Mikaberidze, A., and McDonald, B. A. 2015. Fitness cost of resistance: Impact on management. Pages 77-89 in: Fungicide Resistance in Plant Pathogens. H. Ishil and D. W. Hollomon eds. Springer, Tokyo, Japan.

Monroe, J. S., and Santini, J. B. 1997. A model defining the relationship between temperature and leaf wetness duration, and infection of watermelon by Colletotrichum orbiculare. Plant Dis. 81:739-742.

Nikou, D., Malandrakis, A., Konstantakaki, M., Vontas, J., Markoglou, A., and Ziogas, B. 2009. Molecular characterization and detection of overexpressed C-14 alpha-demethylase-based DMI resistance in Cercospora beticola field isolates. Pestic. Biochem. Physiol. 95:18-27.

Peng, L.-J., Sun, T., Yang, Y.-L., Cai, L., Hyde, K. D., Bahkali, A. H., and Liu, Z.-Y. 2013. Colletotrichum species on grape in Guizhou and Yunnan Provinces, China. Mycoscience 54:29-41.

Perea, S., López-Ribot, J. L., Kirkpatrick, W. R., Mcatee, R. K., Santillán, R. A., Martínez, M., Calabrese, D., Sanglard, D., and Patterson, T. F. 2001. Prevalence of molecular mechanisms of resistance to azole antifungal agents in Candida albicans isolates displaying high-level fluconazole resistance isolated from human immunodeficiency virus-infected patients. Antimicrob. Agents Chemother. 45:2676-2684.

Phoulivong, S., Cai, L., Parinn, N., Chen, H., Abd-Elsalam, K. A., Chukeatirote, E., and Hyde, K. D. 2011. A new species of Colletotrichum from Cordyline fruticosa and Eugenia javanica causing anthracnose disease. Mycotaxon 114. 247-257.

Phoulivong, S., Lei, C., Hang, C., McKenzie, E. H. C., Abdelsalam, K., Chukeatirote, E., and Hyde, K. D. 2010. Colletotrichum gloeosporioides is not a common pathogen on tropical fruits. Fungal Divers. 44:33-43.

Prihastuti, H., Cai, L., Chen, H., McKenzie, E., and Hyde, K. 2009. Characterization of Colletotrichum species associated with coffee berries in northern Thailand. Fungal Divers. 39:89-109.

Qu, B., Li, H., Zhang, J., Xu, Y., Huang, T., Wu, A., Zhao, C., Carter, J., Nicholson, P., and Liao, Y. 2008. Geographic distribution and genetic diversity of Fusarium graminearum and $F$. asiaticum on wheat spikes throughout China. Plant Pathol. 57:15-24.

Ramdial, H., and Rampersad, S. N. 2015. Characterization of Colletotrichum spp causing anthracnose of bell pepper (Capsicum annuиm L.) in Trinidad. Phytoparasitica 43:37-49.

Ristaino, J. B., Madritch, M., Trout, C. L., and Parra, G. 1998. PCR amplification of ribosomal DNA for species identification in the plant pathogen genus Phytophthora. Appl. Environ. Microbiol. 64:948-954.

Rodriguez-Tudela, J. L., Alcazar-Fuoli, L., Mellado, E., Alastruey-Izquierdo, A., Monzon, A., and Cuenca-Estrella, M. 2008. Epidemiological cutoffs and cross-resistance to azole drugs in Aspergillus fumigatus. Antimicrob. Agents Chemother. 52:2468-2472.

Sanglard, D., Kuchler, K., Ischer, F., Pagani, J. L., Monod, M., and Bille, J. 1995. Mechanisms of resistance to azole antifungal agents in Candida albican isolates from AIDS patients involve specific multidrug transporters. Antimicrob. Agents Chemother. 39:2378-2386.

Schmitz, H. K., Medeiros, C. A., Craig, I. R., and Stammler, G. 2014. Sensitivity of Phakopsora pachyrhizi towards quinone-outside-inhibitors and demethylationinhibitors, and corresponding resistance mechanisms. Pest Manage. Sci. 70: 378-388.

Schnabel, G., and Jones, A. L. 2001. The 14 $\alpha$-demethylasse (CYP51A1) gene is overexpressed in Venturia inaequalis isolates resistant to myclobutanil. Phytopathology 91:102-110.

Shin, H., Xu, T., Zhang, C., and Chen, Z. 2000. The comparative study of Capsicum anthracnose pathogens from Korea with that of China. J. Zhejiang Univ. 26:629-634.

Sierotzki, H., and Scalliet, G. 2013. A review of current knowledge of resistance aspects for the next-generation succinate dehydrogenase inhibitor fungicides. Phytopathology 103:880-887.

Song, J., Zhang, S., and Lu, L. 2018. Fungal cytochrome P450 protein Cyp51: What we can learn from its evolution, regulons and Cyp51-based azole resistance. Fungal Biol. Rev. 32:131-142.

Spolti, P., Del Ponte, E. M., Dong, Y., Cummings, J. A., and Bergstrom, G. C 2014. Triazole sensitivity in a contemporary population of Fusarium graminearum from New York wheat and competitiveness of a tebuconazoleresistant isolate. Plant Dis. 98:607-613.

Stammler, G., Cordero, J., Koch, A., Semar, M., and Schlehuber, S. 2009. Role of the Y134F mutation in cyp51 and overexpression of cyp51 in the sensitivity response of Puccinia triticina to epoxiconazole. Crop Prot. 28:891-897.

Su, Y.-Y., Noireung, P., Liu, F., Hyde, K. D., Moslem, M. A., Bahkali, A. H., AbdElsalam, K. A., and Cai, L. 2011. Epitypification of Colletotrichum musae, the causative agent of banana anthracnose. Mycoscience 52:376-382.

Than, P. P., Jeewon, R., Hyde, K. D., Pongsupasamit, S., Mongkolporn, O., and Pwj, T. 2008. Characterization and pathogenicity of Colletotrichum species associated with anthracnose on chilli (Capsicum spp.) in Thailand. Plant Pathol. 57:562-572. 
Wang, Y., Duan, Y. B., and Zhou, M. G. 2015. Molecular and biochemical characterization of boscalid resistance in laboratory mutants of Sclerotinia sclerotiorum. Plant Pathol. 64:101-108.

Weir, B., Johnston, P., and Damm, U. 2012. The Colletotrichum gloeosporioides species complex. Stud. Mycol. 73:115-180.

Xu, X., Lin, T., Yuan, S., Dai, D., Shi, H., Zhang, C., and Wang, H. 2014. Characterization of baseline sensitivity and resistance risk of Colletotrichum gloeosporioides complex isolates from strawberry and grape to two demethylation-inhibitor fungicides, prochloraz and tebuconazole. Australas. Plant Pathol. 43:605-613.

Yang, J. H., Chen, H. Z., Xiao, T., Zhang, W. W., and Zhuang, Y. Q. 2015. Detection of resistance of grape anthracnose pathogen to carbendazim. Acta Agric. Jiangxi 27:32-35.
Yang, Y., Liu, Z., Cai, L., Hyde, K., Yu, Z., and McKenzie, E. 2009. Colletotrichum anthracnose of Amaryllidaceae. Fungal Divers. 39:123-146.

Zhang, C., Diao, Y., Wang, W., Hao, J., Imran, M., Duan, H., and Liu, X. 2017. Assessing the risk for resistance and elucidating the genetics of Colletotrichum truncatum that is only sensitive to some DMI fungicides. Front. Microbiol. 8:1779.

Zhang, C., Liu, Y., Wu, H., Xu, B., Sun, P., and Xu, Z. 2012. Baseline sensitivity of Pestalotiopsis microspora, which causes black spot disease on Chinese hickory (Carya cathayensis), to pyraclostrobin. Crop Prot. 42 . 256-259.

Ziogas, B. N., and Malandrakis, A. A. 2015. Sterol biosynthesis inhibitors: C14 demethylation (DMIs). Pages 199-216 in: Fungicide Resistance in Plant Pathogens. H. Ishii and D. W. Hollomon eds. Springer, Tokyo, Japan. 